\title{
Angels as Warriors in Late Second Temple Jewish Literature
}

[Engel als Krieger in der jüdischen Literatur im Zeitalter des Zweiten Tempels]

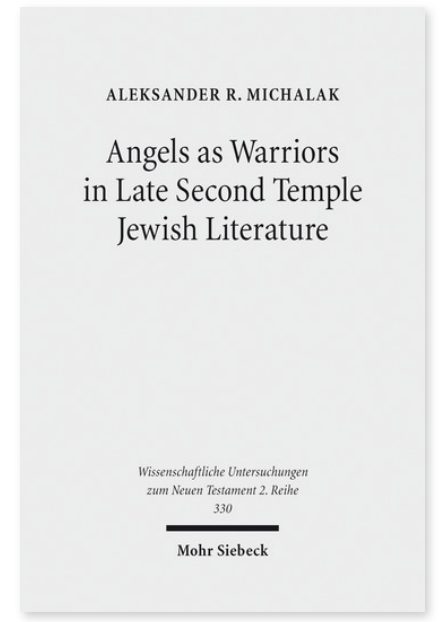

2012. XVI, 323 Seiten. WUNT II 330

ISBN 978-3-16-152148-5

DOI 10.1628/978-3-16-152148-5

eBook PDF 104,00€

ISBN 978-3-16-151739-6

fadengeheftete Broschur 104,00€
Veröffentlicht auf Englisch.

Aleksander Michalak untersucht die Assoziation himmlischer Wesen mit Krieg in jüdischen literarischen Quellen. Der Autor konzentriert sich auf die verschiedenen Darstellungen der kriegerischen Engel in der Literatur im Zeitalter des Zweiten Tempels und thematisiert die Wurzeln dieser Schilderungen, deren Popularität und verschiedene theologische Schlussfolgerungen. Im Mittelpunkt stehen dabei Michael, Gabriel und die zahllosen anonymen angriffslustigen Engelsfiguren, die in den biblischen und apokryphen Texten erscheinen. Die bildliche Darstellung militärischer Handlungen durch Engel wird innerhalb des Kontextes der Primärquelle erforscht, aber auch der weitere »angelologische« Hintergrund wird in die Betrachtung einbezogen. Aleksander Michalak zeigt, dass eine Teilnahme der Engel an einem eschatologischen Krieg erwartet wurde. Er stellt außerdem ihre Rolle in diesem Konflikt dar. Ebenso weist er auf die Assoziation von Engelskriegern mit bestimmten jüdischen Helden, den Schutz der Mauer von Jerusalem durch die Engel und die Militärmacht der Engel, sowie auf ihre Rolle sowohl als Beschützer als auch als Zerstörer hin.

Aleksander R. Michalak Born 1974; 2001 graduated from University of Gdańsk; 2006 PhD in ancient history and 2011 PhD in Religions and Theology from Trinity College Dublin; 2009-10 working on his habilitation thesis at the University of Tübingen (Faculty of Catholic Theology); 2011 Andrew Mellon Fellow in the Albright Institute of Archaeological Research in Jerusalem.

Jetzt bestellen:

https://mohrsiebeck.com/buch/angels-as-warriors-in-late-second-temple-jewish-literature-9783161521485?no_cache=1 order@mohrsiebeck.com

Telefon: $+49(0) 7071-923-17$

Telefax: $+49(0) 7071-51104$ 